\title{
Recycling Of Ceramic Tiles And Marble Powder Waste As Partial Substitution In Concrete
}

\author{
Bilawal, SOOMRO \\ Department of Civil Engineering, Mehran University of Engineering and Technology SZAB \\ Khairpur Mir's, 66020 Sindh, Pakistan \\ bilawalali357@gmail.com \\ Sajjad Ali, MANGI \\ Department of Civil Engineering, Mehran University of Engineering and Technology SZAB \\ Khairpur Mir's, 66020 Sindh, Pakistan \\ Sajjad.nec@gmail.com \\ Rashid Ali, BAJKANI \\ Department of Civil Engineering, Mehran University of Engineering and Technology SZAB \\ Khairpur Mir's, 66020 Sindh, Pakistan \\ h Rashidbajkani1999@gmail.com \\ Abdul Qudoos, JUNEJO \\ Department of Civil Engineering, Mehran University of Engineering and Technology SZAB \\ Khairpur Mir's, 66020 Sindh, Pakistan \\ aqudoos52ce@gmail.com
}

\begin{abstract}
Recycling the waste has been one of the most influential aspect affecting global conditions of the world. In the world of Civil Engineering, it serves the purpose of preservation of the natural building materials such as Sand, Stones, etc. Fair amount of work been done on utilization of the waste such as Fly ash, marble waste, tiles waste, plastic, etc. used as different forms of replacement, provokes the need of work still to be done. So much of the work has been done on wastes available from Marble and Tiles. The combined effect of waste marble powder (M.P) and Ceramic tile waste (CTW) as partial replacement of Cement (10\%) and Coarse Aggregates (10\%,20\%,30\% respectively) is to be observed and analyzed. The obtained results will be compared with the conventional cement concrete at 7 and 28 days of Curing. Total 24 number of cylinders casted and tested for their workability and Compressive strength. The Workability of Concrete with replacement decreased with increasing ratio of replacement as well as its Compressive Strength. The Compressive strength of concrete with replacement is approximately of same value as that of Conventional Concrete at $(10 \%+10 \%)$ partial substitution ratio.
\end{abstract}

\section{Keywords}

Recycling, Marble Powder waste, CTW, Compressive Strength, Substitution

\section{Introduction}

Concrete requires to have the constituent materials like Cement, Aggregates and Water for Concrete production [1], [2]. While it was observed that there is continuous reduction in the amounts of naturally occurring constituents used in production of Concrete [2], [3]. We are losing the amount of aggregates and water annually. In that regards, the reduction in natural resources; that day is not that far where we may get the shortage of the amount of aggregates and water required for Construction Industry, which make this issue an alarming situation [2], [4]. Since they are naturally occurring substances therefore it is very difficult for the Researchers to find their perfect substitute in order to cover up the expected deficiencies [2].

Recycling the waste is one technique that can be followed to fulfil the purpose of preservation of the constituent natural materials of Concrete. Also there are different types of other materials that are being experimentally used as a substitution to cement or sand or aggregates such as marble, Fly 
ash, tiles, lime stone, plastic, etc. which actually are hazardous wastes that contribute to the pollution in our surroundings [2], [4]. To add solution to these harmful effects produced by wastes, Around the globe the 3R concept (reduce-reuse-recycle) is being appreciated which encourages the Society to use recyclable materials more [4]. Reviewing the nature of the materials, Marble and Ceramic tiles can be said as recyclables. It is a strong solid waste having compact unit structures, should serve the purpose of recycling [2], [3]. Advantages of Recycling includes protection of the natural resources, Energy preservation, reduction in the amount of pollutant wastes, Economically favorable and investment for the future [4], [3]. For instance, Recycling the waste marble powder causes reduction in the cost of production of concrete and lowers the amount of cleaning it required from the environment [5]. In this research waste materials of marble and Ceramic tiles have been utilized as partial substitution of Cement and Coarse aggregates respectively which most probably is cheaper as well as environmentally friendly.

\subsection{Aim and Objectives of the Study \\ 1.1.1 Aim}

The aim of this study is to Utilize Marble powder as cement replacement and Ceramic Tiles waste as coarse aggregate replacement in Concrete for the development of sustainable and green Construction.

\subsubsection{Objectives of the Study}

To achieve the aim of this study following objectives are to be fulfilled:

1) To evaluate the Physical properties of materials such as Specific Gravity, Water Absorption, Bulk Density and Sieve Analysis.

2) To determine Workability and Compressive Strength of Concrete with or without marble and tile waste.

3) To recommend suitable percentage replacement of Tile Waste with Marble powder.

The Laboratory work to be carried out took at least 1-2 months. It involved testing of the materials, preparation of samples according to standards, casting of the concrete and partially replaced concrete samples and finally the specimen left in impurities free water for curing process. The curing process for the prepared samples was scheduled for 7 and 28 days which means that at least a month was invested in Curing. There was also some time required for the testing of these prepared samples and results were analyzed properly. For this purpose, concrete was batched, mixed transported compacted and finished in laboratory in stringent condition using ASTM standards. Tests were performed at different curing ages and the compression tests were done in Compression testing machine. There is a huge traffic for further research in recycling which makes sustainable and green materials, generating employment from marble waste concrete production ensures provision of income to urban and rural mass while arresting further pollution of the environment [6], [7]. Further research could be done on fire resistance, acid resistance, durability and flexural strength of this kind of ceramic waste tile concrete [8]. Method of replacement can solve hindrances such as crisis due to waste disposal.
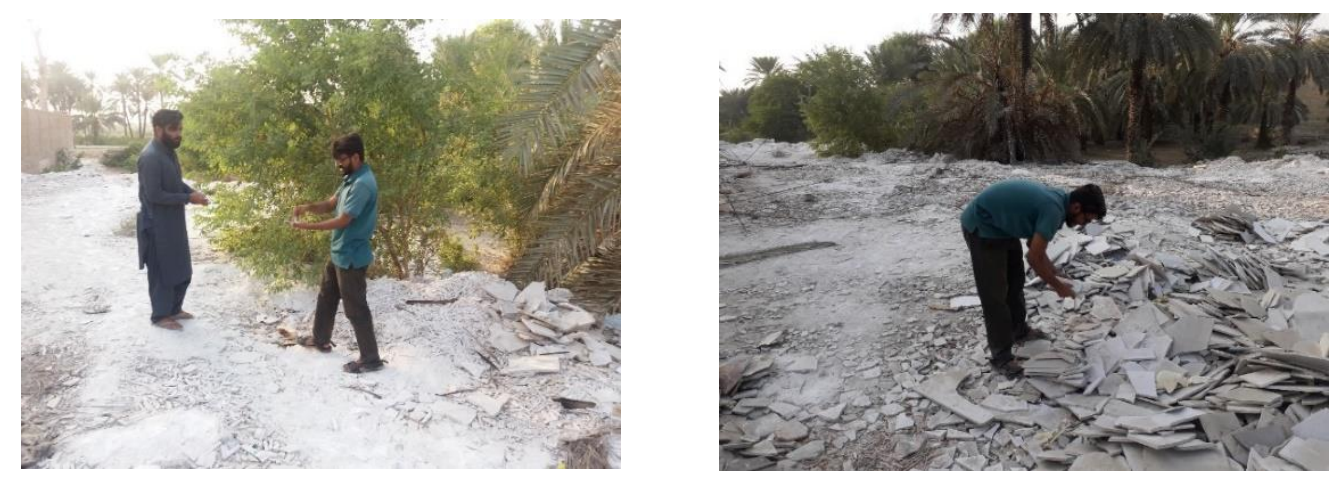

Figure 1. Marble and Ceramic Tile Waste at the Industry 


\section{Research Methodology}

\subsection{General}

It involves discussion on the practical work to be done in the Laboratory to evaluate the results practically. It contains Selection of the materials, Properties of the materials, Sample Preparation and No. of Samples to be prepared, Objective Tests to be performed, Equipment and their specifications and Flow Chart of the Objectives.

This is the most important move as for as the credibility of this thesis or research is concerned. Because, it includes the whole strategy of how the work is going to be performed and handled with necessary precautions and standardized procedures.

The Flow Chart of the Methodology is given on the next page.

\subsection{Working Mechanism}

The working process takes two stages:

1. Material Testing

2. Sample Preparation and Sample Testing

\subsubsection{Material Testing}

It involves selection of the suitable materials for the preparation of samples by different types of test such as Specific gravity, Water absorption, Bulk density, Sieve analysis, etc.

\subsubsection{Sample Preparation and Sample Testing}

In continuation, after checking for the physical properties of materials the work proceeds further and sample preparation takes place. Total 24 number of samples of cylinder are to be prepared, 12 at each 7- and 28-days curing. Further Clarification of samples is as; out of 12 samples, 3 cylinders of control mix while 3 at each $10 \%(\mathrm{M} . \mathrm{P})+10 \%(\mathrm{C} . \mathrm{T}), 10 \%(\mathrm{M} . \mathrm{P})+20 \%(\mathrm{C} . \mathrm{T})$ and $10 \%($ M.P $)+30 \%($ C.T) replacements respectively.

Figure 2. Research Methodology Flow Chart

\subsection{Materials}

For experimental study, Ordinary Portland Cement of fine quality is used manufactured by "Lucky Cement Factory". The sand which is locally available and passing through $4.75 \mathrm{~mm}$ and retained on $0.0075 \mathrm{~mm}$ sieve is used. The Coarse aggregate passing through $20 \mathrm{~mm}$ sieve size and retained on $4.75 \mathrm{~mm}$ sieve is selected for the preparation of Sample. Any debris available is removed from Aggregates and stored in dry condition. In this research, Marble powder acts as a partial substitution to Cement (10\%). The marble used in preparation of the samples is obtained from industries and Quarry sites. The powdered form wastes developed is taken from there and then utilized as per requirement. Also, this study focuses on ceramic tile waste (C.T) as partial coarse aggregates replacement for concrete production passing through $20 \mathrm{~mm}$ sieve size and retained on $4.75 \mathrm{~mm}$ sieve is selected for the preparation of Sample. Potable Water was used obtained from Department of Civil Engineering MUET SZAB Khairpur Mir's. Water play major role in the strength of concrete; ordinary clean water was used in $\mathrm{W} / \mathrm{C}$ ratio of 0.5 was adopted during the mix of concrete and Water for Curing process was also adopted from there as well.

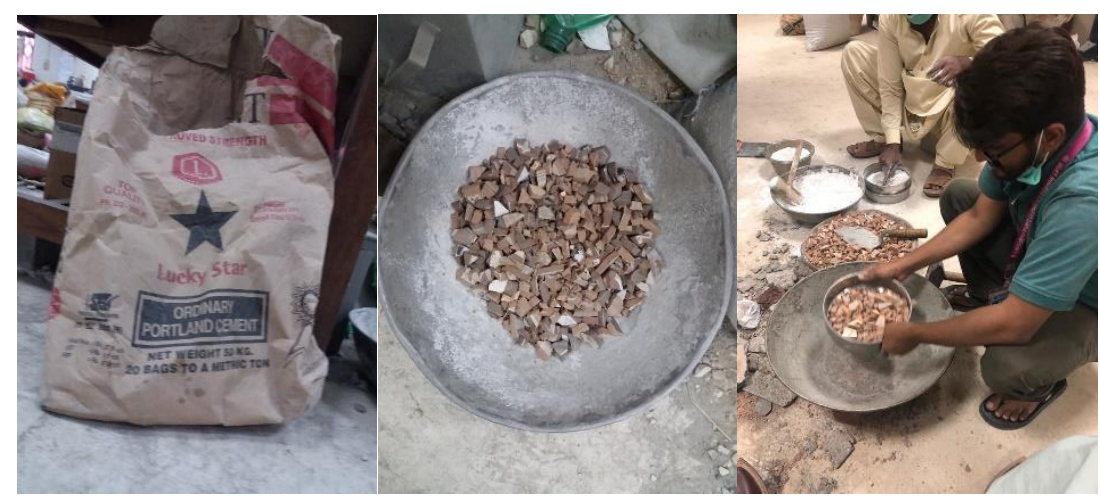

Figure 3. Materials for the mix 
Table 1. Properties of Marble Powder [17]

Specific gravity 2.83-2.87

Silicon (\%) $\quad 0.3347$

Iron Oxide (\%) $\quad 0.4093$

Calcium $\quad 97.7820$

Carbonate (\%)

Bulk density $\quad 1.3-1.5 \mathrm{gm} / \mathrm{cm} 3$
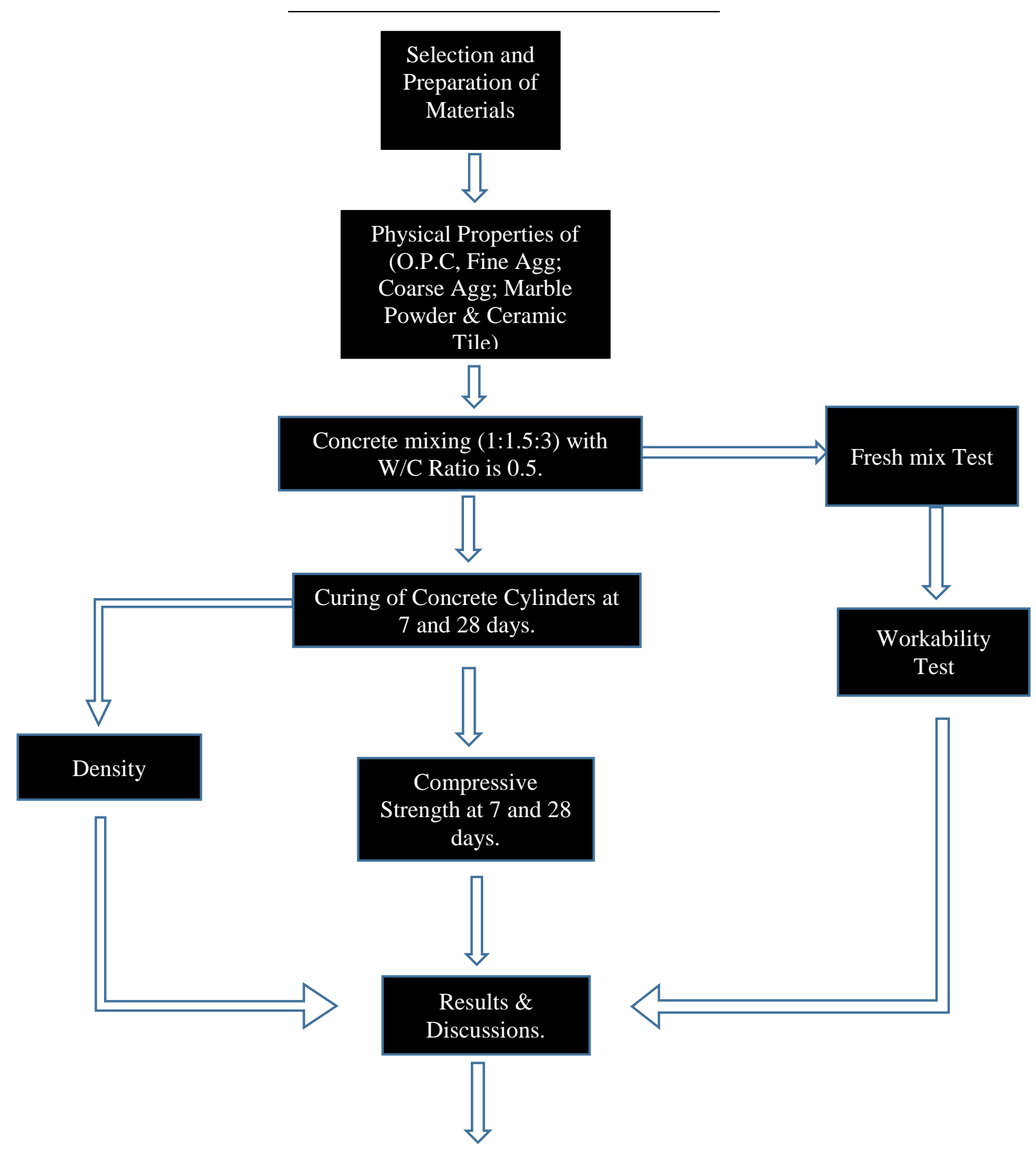

Conclusion 
Table 2. Properties of Ceramic Tiles

\begin{tabular}{cc}
\hline Description & $\begin{array}{c}\text { Test } \\
\text { Results }\end{array}$ \\
Specific & 1.9 \\
gravity & \\
Bulk density & $1.1-$ \\
& $1.4 \mathrm{gm} / \mathrm{cm} 3$ \\
Water & $12 \%$ \\
Absorption & \\
\hline
\end{tabular}

\subsection{Casting and Curing}

Every batch contained 3 cylinders with total of 8 batches were prepared. Weighing process was employed to measure the material for casting of control specimen. Steel molds were used for the casting of the specimens. Before pouring concrete, molds were oiled so that the stripping of mold should be easy. Three layers were made for filling the molds each layer was compacted by 25 blows by $16 \mathrm{~mm}$ diameter rod. Concrete were taken out of molds after 24 hours and were taken for curing.

After the complete curing process, the specimens were tested at the age of 7 and 28 days to check the strength at different ages.

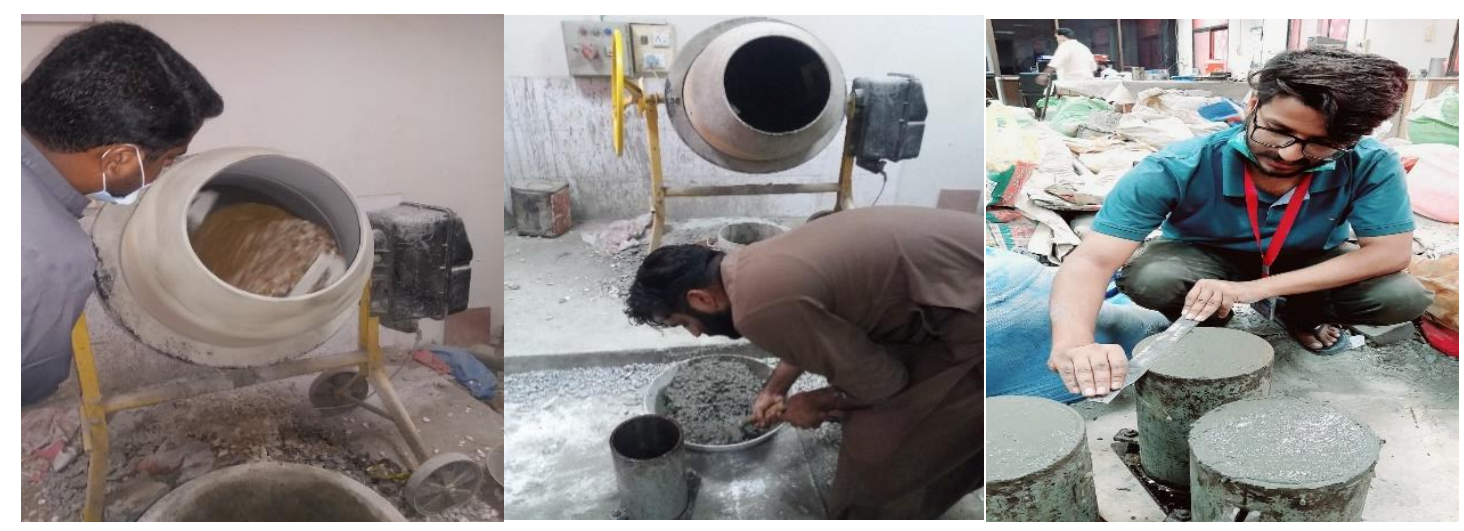

Figure 4. Mixing and Casting

\subsection{Testing Procedure \\ 2.5.1 Workability Test}

Workability is defined as the ease in placement and transportation of concrete means the concrete which can be placed and can be compacted easily. Slump Cone test is conducted for workability of Concrete. Medium workability of Concrete is suitable for Construction according to standards. 
Three type slumps can form when the slump cone is lifted which are True Slump, Shear Slump and Collapsible Slump. Out of the three True Slump is preferred having medium workability. The Standard for this Fresh Mix Concrete test is ASTM C-143 [9].

Figure 5. Slump Cone and Tamping Rod

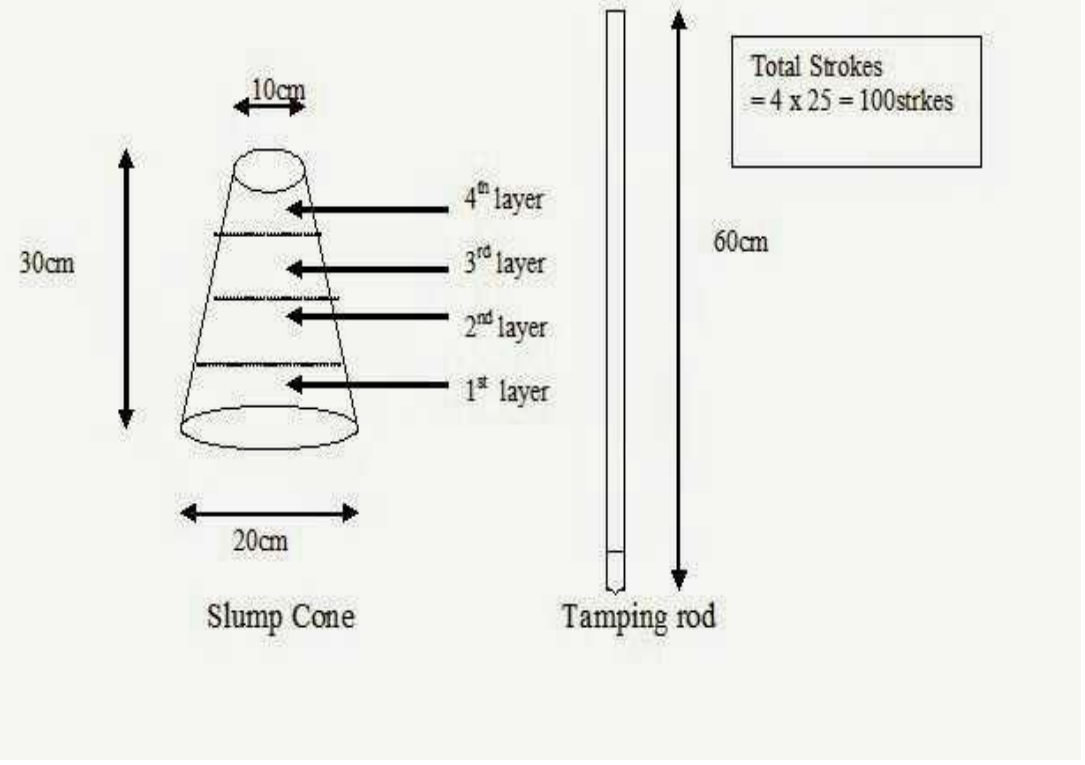

\subsubsection{Compressive Strength Test}

Compressive strength test was conducted as per ASTM C-39 [10]. The test is conducted using Compression testing machine of $2000 \mathrm{KN}$ capacity at a loading rate of $1.3 \mathrm{~mm} / \mathrm{min}$. Mechanical behavior of concrete is studied; cylinders were casted and cured for 7 and 28 days. Compressive strength of concrete cylinder is tested at different percentages of CTW as coarse aggregate and $10 \%$ marble powder as partial cement content in concrete. The strength of concrete cylinders is tested at 7- and 28-days curing. For testing the compressive strength, Compression testing machine is used.
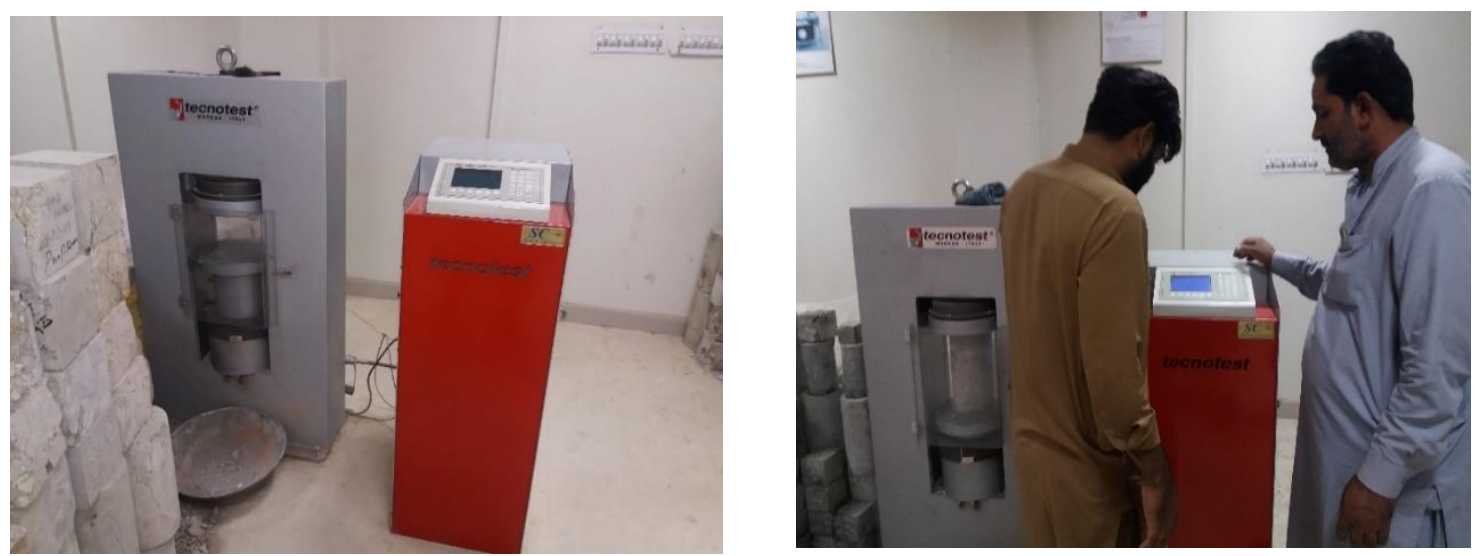

Figure 6. Compression Testing Machine 
Table 3. Number of Cylindrical Samples (150x300) mm3 for Compressive Strength

$\begin{array}{ccccc}\begin{array}{c}\text { Sample } \\ \text { Code }\end{array} & \begin{array}{l}\text { Replacement } \\ \text { of Marble (\%) }\end{array} & \begin{array}{l}\text { Replacement } \\ \text { of Ceramic } \\ \text { Tiles }(\%)\end{array} & \begin{array}{c}\text { Curing at } \\ 7 \text { days }\end{array} & \begin{array}{c}\text { Curing } \\ \text { at } 28 \\ \text { days }\end{array}\end{array}$

$\begin{array}{ccccc}\mathbf{C}_{1} & 0 & 0 & 3 & 3 \\ \mathbf{C}_{2} & 10 & 10 & 3 & 3 \\ \mathbf{C}_{3} & 10 & 20 & 3 & 3 \\ \mathbf{C}_{4} & 10 & 30 & 3 & 3 \\ & & & & \text { Total }=24\end{array}$

\section{Result and Discussion}

\subsection{Slump Test}

From previous findings, Workability was reduced when M.P and CTW were individually used in Concrete as partial replacement [2]. By taking this point in view it was obvious that Workability will decrease if their combination is used. Hence with increasing percentage of waste being used in concrete the workability got reduced which is a negative behavior of concrete with replacement.

Table 4. Slump findings during Slump Cone test

\begin{tabular}{ccc}
\hline Specimen Code & Mix Type & Slump Value $(\mathrm{mm})$ \\
$\mathrm{C}_{1}$ & Control mix & 60 \\
$\mathrm{C}_{2}$ & $10 \%(\mathrm{M} . \mathrm{P})+10 \%$ (C.T) & 50 \\
$\mathrm{C}_{3}$ & $10 \%(\mathrm{M} . \mathrm{P})+20 \%$ (C.T) & 40 \\
$\mathrm{C}_{4}$ & $10 \%(\mathrm{M} . \mathrm{P})+30 \%$ (C.T) & 30 \\
\hline
\end{tabular}

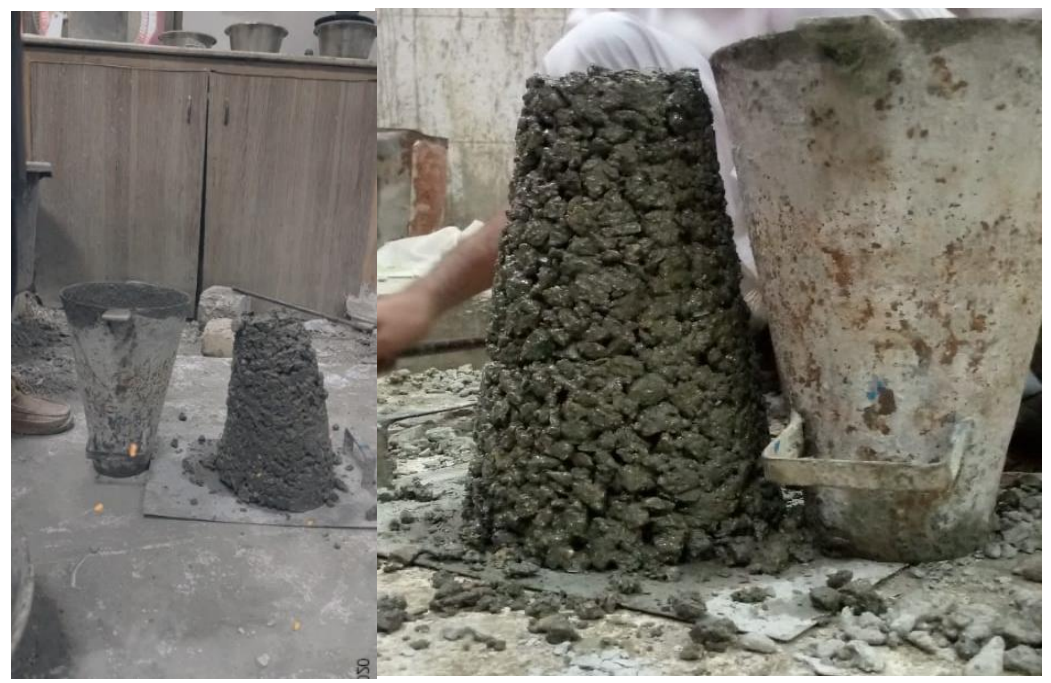




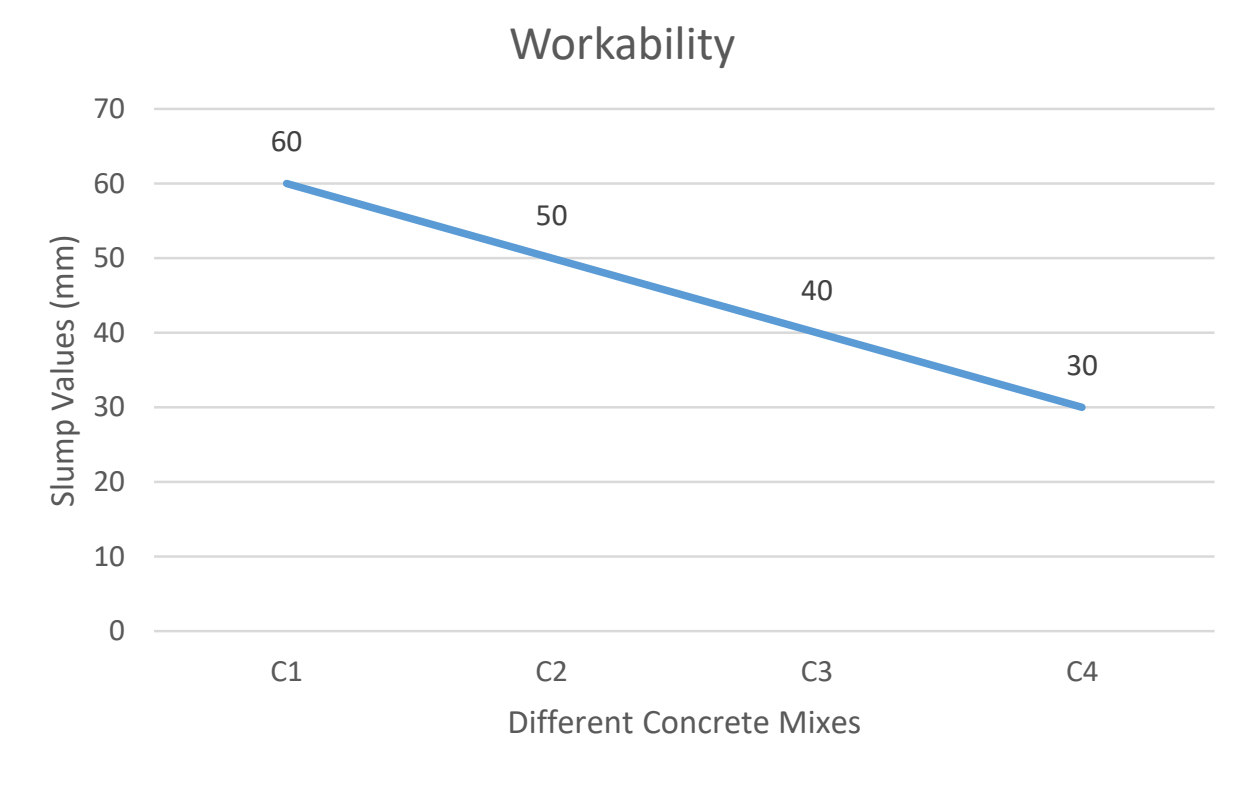

Figure 7. Shape of Slump

Figure 8. Slump value Comparison

\subsection{Compressive Strength Test}

As we know that concrete is rich in compression, so it is essential to find the compressive strength of concrete, hence test is performed to evaluate the compressive strength of concrete. These tests were performed in Civil Engineering Concrete laboratory. In this test, the specimen was placed in Electronic Compression testing machine. The machine is started it begins to apply a gradually increasing load on specimen. The maximum load or ultimate load and strength at which cylinder fails was recorded. The average of three values at each percentage replacement were calculated and the average value was considered as a final Curing value.

From previous Studies Compressive Strength of the Concrete with partial substitution of marble powder as well as ceramic tile individually has yielded positive results by giving increment in Compressive Strength values [3], [11], [12].

It was up to $10 \%$ marble powder replacement with cement that yielded increase in Compressive Strength and that for ceramic tile waste was up to 30\% [13], [14].

Table 5. Results of Average Compressive Strength Test.

\begin{tabular}{cccc}
\hline Specimen Code & Mix Type & $\begin{array}{c}\text { Average } \\
\text { Compressive } \\
\text { Strength at } 7 \text { days } \\
(\mathrm{MPa})\end{array}$ & $\begin{array}{c}\text { Average } \\
\text { Compressive } \\
\text { Strength at 28 days } \\
\text { (MPa) }\end{array}$ \\
$\mathrm{C}_{1}$ & Control mix & 18.83 & 22 \\
$\mathrm{C}_{2}$ & $\begin{array}{c}10 \%(\mathrm{M} . \mathrm{P})+10 \% \\
(\mathrm{C} . \mathrm{T})\end{array}$ & 17.72 & 21 \\
$\mathrm{C}_{3}$ & $\begin{array}{c}10 \%(\mathrm{M} . \mathrm{P})+20 \% \\
(\mathrm{C} . \mathrm{T})\end{array}$ & 16.91 & 19 \\
$\mathrm{C}_{4}$ & $\begin{array}{c}10 \%(\mathrm{M} . \mathrm{P})+30 \% \\
(\mathrm{C} . \mathrm{T})\end{array}$ & 17.63 & 20 \\
\hline
\end{tabular}


Figure 9. Average Compressive Strength Value Comparison

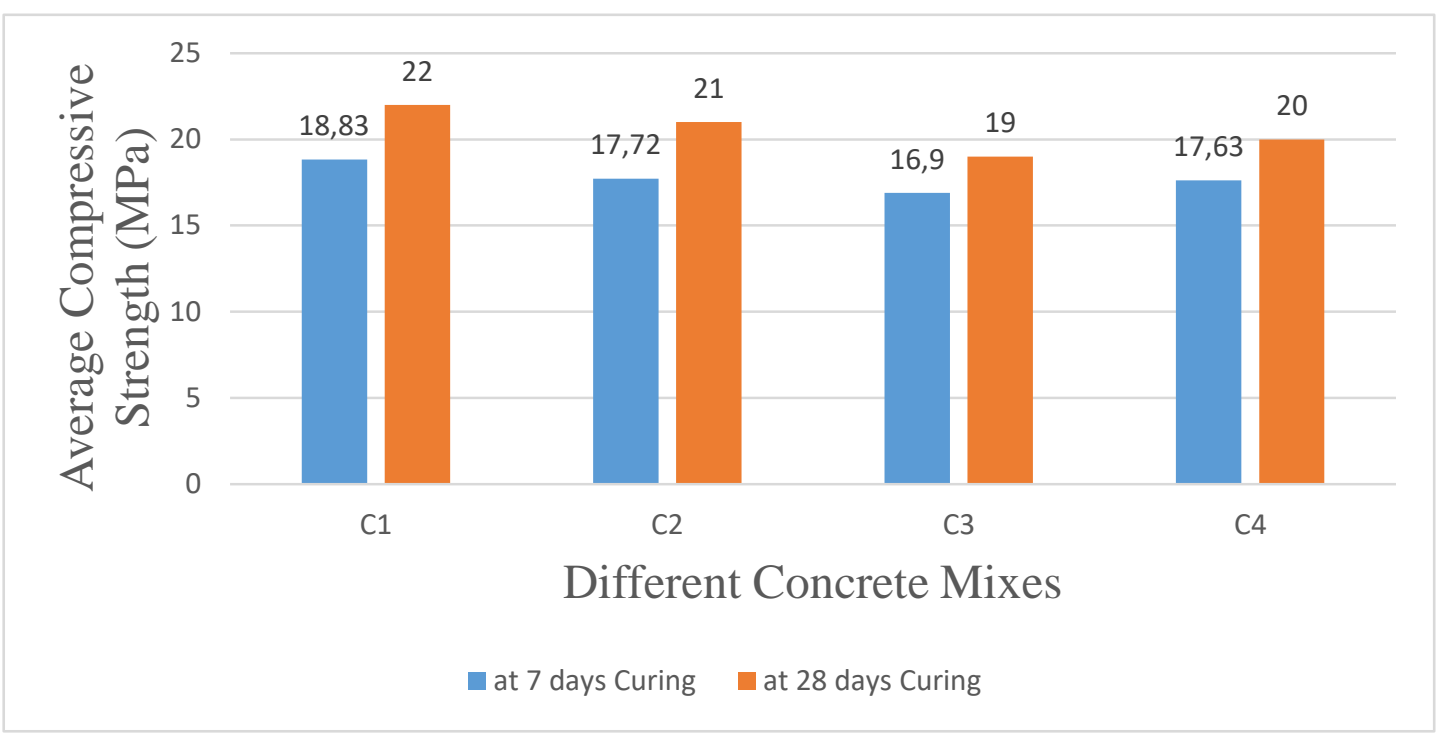

Since, all the test results have been successfully incorporated, it is time to analyze them at once with respect to different partial mix ratios to decide for objective three. $\mathrm{C}_{1}$ specimen performed best among the partially substituted concrete in terms of Compressive Strength and density having better workability as well.

$\mathrm{C}_{3}$ performed better as compare to $\mathrm{C}_{2}$ in terms of Compressive Strength but with the lowest results in density as well as lower workability.

$\mathrm{C}_{2}$ samples had the lowest Compressive strength values. Hence, it is clear from the discussion that $\mathrm{C}_{1}$ ratio which is $10 \%$ (M.P) $+10 \%$ (C.T) as partial replacement in concrete is the best among the lot.

\section{Conclusions and Recommendations \\ 4.1 Conclusions}

In this study, the effect of using marble powder and ceramic tiles waste on properties of concrete were studied and it can be concluded that:

1. The Compressive strength of concrete with replacement is approximately same as that of Conventional Concrete which is $93 \%$ at $(10 \%+10 \%)$.

2. The Workability as well as Compressive Strength of Concrete decreases with increasing ratio of replacement.

3. Comparing the partially replaced Concrete, with increasing ratio of replacement Density of specimen also reduced.

4. Partially Substituted Concrete at the Ratio of $(10 \%+10 \%)$ substitution performs better than other replacements used.

5. The Water Absorption as well as Specific gravity values of Ceramic Tiles are lower than the conventional Coarse aggregates.

6. Further Considering the test results, it can be transpired that $10 \%+10 \%$ replacement is the recommended ratio if opted for the combination.

\subsection{Recommendations}

1. Through the observation of results of this study, it can be recommended that marble powder waste as well as Ceramic tile waste can be utilized in Concrete.

2. Further Considering the test results, it can be transpired that $10 \%+10 \%$ replacement is the recommended ratio if opted for the combination.

\section{References}

[1] P. C. Varghese, Building Materials. New Delhi: PHI Learning Private Limited, 2015.

[2] M. Daniyal and S. Ahmad, "Application of Waste Ceramic Tile Aggregates in Concrete," Int. J. Innov. Res. Sci. Eng. Technol, vol. 4, no. 1212808-12815, 2015.

[3] G. C. Ulubeyli and R. Artir, "Properties of Hardened Concrete Produced by Waste Marble 
Powder," Procedia - Soc. Behav. Sci., vol. 195, pp. 2181 - 2190, 2015.

[4] A. Ragossnig, "What is the real scope of waste management?," Waste Manag. Res, vol. 35, no. 11, pp. 1097-1098, 2017.

[5] N. T. Seghir, M. Mellas, Ł. Sadowski, A. Krolicka, A. Zak, and K. Ostrowski, "The utilization of waste marble dust as a cement replacement in air-cured mortar," Sustain., vol. 11, no. 8, pp. 1-14, Apr. 2019, doi: 10.3390/su11082215.

[6] A. K. Thakur, A. Pappu, and V. K. Thakur, "Resource efficiency impact on marble waste recycling towards sustainable green construction materials," Current Opinion in Green and Sustainable Chemistry, vol. 13. Elsevier B.V., pp. 91-101, Oct. 2018, doi: 10.1016/j.cogsc.2018.06.005.

[7] P. Ramanaidu, P. Murahari Krishna, M. Tech student, and A. Professor, "Partial Replacement of Aggregates with Ceramic Tiles and Rebutted Tyre Waste in Concrete," Int. J. Eng. Trends Appl., vol. 5, no. 3, pp. 71-87, 2018.

[8] M. Kabir, "An Assessment Of The Properties Of Concrete Made With Ceramic Waste As Aggregate In Partial Fulfillment Of The Requirements For The Award Of A Master Degree In Construction Technology," Ahmadu Bello University, 2016.

[9] ASTM C-143/C143M-20, "Standard Test Method for Slump Hydraulic- Cement Concrete, ASTM International, West Conshohocken, PA, 2020," ASTM Internasional, 2020.

[10] ASTM C-39/C39M-20, "Standard Test Method for Compressive Strength Of Cylindrical Concrete Specimens, ASTM International, West Conshohocken, PA, 2020," ASTM Internasional, 2020. .

[11] K. N. Davara, R. P. Kikani, Y. R. Tank, and A. Raturi, "A Review on Utilization of Marble Waste Powder as a Partial Replacement of Cement in Glasscrete Concrete," Int. J. Adv. Eng. Res. Dev., vol. 4, no. 11, pp. 1322-1328, 2017.

[12] N. Ganesan, A. Nagar, and A. Nagar, "Studies on Strength Characteristics on Utilization of Waste Materials As Coarse Aggregate in Concrete," Int. J. Eng. Sci. Technol, vol. 3, no. 7, pp. 5436-5440, 2011.

[13] R. Singh, M. Bhutani, and T. Syal, "Strength evaluation of concrete using Marble Powder and Waste Crushed Tile Aggregates," Int. J. Sci. Emerg. Technol. with Latest Trends, vol. 20, no. 118-28, 2015.

[14] R. Kumar and S. K. Kumar, "Partial Replacement of Cement with Marble Dust Powder," Int. J. Eng. Res. Appl, vol. 5, no. 8, pp. 106-114, 2015. 